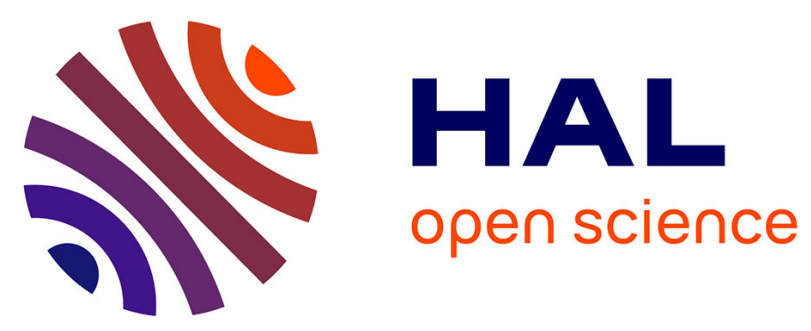

\title{
Hundreds of meter-long low-loss silicon-core optical fiber
}

Maryna Kudinova, Géraud Bouwmans, Rémi Habert, Stéphane Plus, Karen

Baudelle, Remy Bernard, Bertrand Chazallon, Andy Cassez, Hicham El

Hamzaoui, Olivier Vanvincq, et al.

\section{- To cite this version:}

Maryna Kudinova, Géraud Bouwmans, Rémi Habert, Stéphane Plus, Karen Baudelle, et al.. Hundreds of meter-long low-loss silicon-core optical fiber. Conference on Optical Components and Materials XVII, Feb 2020, San Francisco, United States. 10.1117/12.2544173 . hal-02957806

\section{HAL Id: hal-02957806 https://hal.science/hal-02957806}

Submitted on 16 Dec 2020

HAL is a multi-disciplinary open access archive for the deposit and dissemination of scientific research documents, whether they are published or not. The documents may come from teaching and research institutions in France or abroad, or from public or private research centers.
L'archive ouverte pluridisciplinaire $\mathbf{H A L}$, est destinée au dépôt et à la diffusion de documents scientifiques de niveau recherche, publiés ou non, émanant des établissements d'enseignement et de recherche français ou étrangers, des laboratoires publics ou privés. 


\title{
Hundreds of meter-long low-loss silicon-core optical fiber
}

\author{
Maryna Kudinova ${ }^{\mathrm{a}}$, Géraud Bouwmans ${ }^{\mathrm{a}}$, Rémi Habert ${ }^{\mathrm{a}}$, Stéphane Plus ${ }^{\mathrm{a}}$, Karen Baudelle ${ }^{\mathrm{a}}$, \\ Rémy Bernard ${ }^{\mathrm{a}}$, Bertrand Chazallon ${ }^{\mathrm{a}}$, Andy $\mathrm{Cassez}^{\mathrm{a}}$, Hicham El Hamzaoui ${ }^{\mathrm{a}}$, Olivier \\ Vanvincq $^{\mathrm{a}}$, Johann Troles $^{\mathrm{b}}$, and Laurent Bigot ${ }^{\mathrm{a}}$ \\ ${ }^{a}$ Univ. Lille, CNRS, UMR 8523 - PhLAM - Physique des Lasers Atomes et Molécules, F-59000 \\ Lille, France \\ ${ }^{\mathrm{b}}$ CNRS, ISCR - UMR 6226, Univ Rennes, F-35000 Rennes, France
}

\begin{abstract}
Hybrid optical fibers, i.e. optical fibers that combine, in the same structure, glass with crystal, metal, polymer or a second type of glass, open access to a wide range of optical properties or optical functions not accessible to common single-glass-made optical fibers. Silicon-core fibers are one type of hybrid fibers that have been intensively studied since 2006 with the aim to take benefit of the mid-infrared transparency of silicon or to implement opto-electrical functions in the optical fiber itself. Some of the unique optical properties of these semiconductor-core fibers have been demonstrated but it is admitted that optical losses are still today a drag on the rise of performances and hence devote specific attention. Post-processing based on laser or thermal annealing can be applied on the as-drawn fibers to improve core crystallinity and then reduce optical losses. However, such processing techniques have been demonstrated on centimeter-long fibers only. In the present paper, we demonstrate as-drawn silicon-core fiber with loss level below $0.2 \mathrm{~dB} / \mathrm{cm}$ on the $1250-1650 \mathrm{~nm}$ wavelength range, this fiber being continuously manufactured over length exceeding one hundred of meters. Several fibers have been fabricated from a rod-in-stack approach and different core dimensions ranging from about 0.8 to $3.4 \mu \mathrm{m}$ have been successively realized and extensive characterizations (XRD, micro-Raman spectroscopy, TEM and ToF-SIMS analysis) have been conducted on the $3.4 \mu \mathrm{m}$ core fiber. The crystalline state of the core, the absence of oxygen contamination and the optical transmission from 1.1 to $4 \mu \mathrm{m}$ will be presented.
\end{abstract}

Keywords: Hybrid optical fibers, Semiconductor optical fibers, Silicon-core optical fibers

\section{INTRODUCTION}

Silica-based optical fibers are characterized by ease of use, exceptional guiding properties - especially a very low attenuation - and well-mastered manufacturing processes that led to their widespread use in Telecom, sensors and light sources application domains. These qualities, together with the wide panel of optical components available today to interface them with light sources, detectors and special optically active/passive systems, explain why when people are considering the implementation of new functions in fiber optics components, they try to make them as much compatible as possible with the existing silica fibers. This is typically the philosophy of hybrid fibers that are constituted by a silica basis combined with a more exotic material such as a soft glass, a polymer, a metal or a semiconductor. ${ }^{1}$ Silica/silicon optical fibers are part of this special branch of the optical fiber family and have been the subject of numerous works since 2006. ${ }^{2,3}$ These works are motivated by the attractive optical and electrical properties of silicon, very different from the silica's ones, that allow to target optical functions such as light sources in the Mid-Infrared (Mid-IR) or in-fiber optoelectronic integration. The very different properties of silica and silicon are also observed in the thermo-structural domain, which is illustrated, for example, by the melting point of silicon which is well below that of silica. Such a difference makes the combination of the two materials quite complicated in the optical fiber geometry. However, Ballato and co-workers demonstrated in the past that a quite simple approach such as the Molten Core Method (MCM) permits, quite contra-intuitively,

Further author information (Send correspondence to L. Bigot)

E-mail: laurent.bigot@univ-lille.fr, Telephone: +33 (0)362531535

M. Kudinova is now at Prysmian Group, Parc des Industries Artois Flandres, 644 boulevard Est, Billy Berclau, 62092

Haisnes Cedex, France 
to manufacture such exotic fibers using conventional fiber drawing equipments. ${ }^{4}$ These works and those based on fibers developed by High Pressure Chemical Vapor Deposition (HPCVD) method have demonstrated the potentialities of silicon-core fibers and also raised some limitations for those applications, such as the difficulty to reach a small core size together with the obtention of reasonable background losses. ${ }^{5}$ Hence, besides impressive results already published, there is still a need today for a better understanding of the link between optical properties and manufacturing technique. It is the aim of this work to present some of the results recently obtained by our group in this context.

\section{ALTERNATIVE APPROACHES FOR THE REALIZATION OF SILICON-CORE FIBERS}

As has been previously recorded, one challenge when trying to synthesize a silica/silicon hybrid fiber lies in the very different thermal behaviors of the two materials, which can be at the origin of cracks, inhomogeneous distribution of the two materials, bubbles and uncontrolled structural properties along the fiber length. When using solid materials (silicon rod and silica tubes) as starting materials, these unwanted phenomena are supposed to be facilitated by the air gap existing between the silicon and silica materials. We hence developed a first original approach so as to try to limit the presence of such a gap.

\subsection{Assembly with in a Sol-Gel -made porous silica material}

The basic idea of the first technique consists in obtaining an all-solid silicon/silica preform without heating the materials at a temperature higher than the one of the silicon melting point $\left(1414^{\circ} \mathrm{C}\right)$. So as to reach this goal, the proposed approach consists in the sintering of a porous silica material onto a silicon rod. The starting silica material is a porous rod synthesized by the Sol-Gel polymeric route, following the general protocol described in ref. ${ }^{6}$ This porous rod is drilled in order to obtain a non-through hole in which a commercially-available silicon rod can be inserted. In the present example, the hole is about $3 \mathrm{~mm}$ in diameter whereas the silicon rod is $2 \mathrm{~mm}$ in diameter. Once the core material is inserted, the whole assembly is processed between 900 and $1350^{\circ} \mathrm{C}$ under controlled atmosphere so as to remove hydroxyl groups from the porous silica network and consolidate it into a transparent glass. During the last part of this process, the silica network shrinkages onto the silicon rod making, at the end, an all-solid silicon core preform available for drawing. Such a drawing can then be done on a conventional drawing tower at a temperature close to $2000^{\circ} \mathrm{C}$. The resulting fiber obtained in the example proposed here is about $1 \mathrm{~mm}$ in diameter and the core diameter is about $150 \mu \mathrm{m}$. A Scanning Electron Image (SEM) of such a fiber is illustrated on Fig. 1.

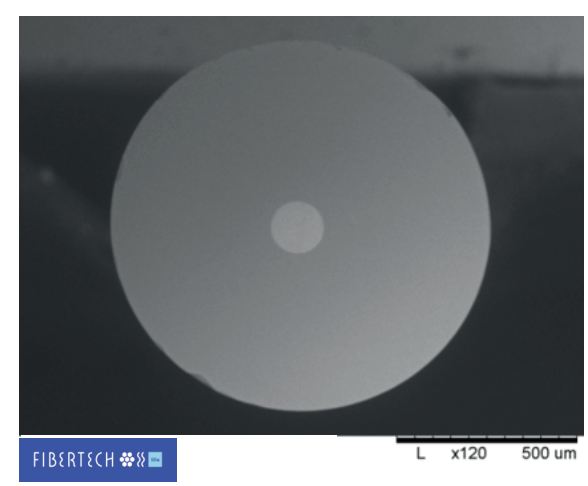

Figure 1. SEM image of a silicon-core fiber obtained by sintering of a Sol-Gel -made silica cladding onto a silicon rod and drawing the resulting preform into a fiber.

One can note the good quality of the silicon/silica interface, which indicates that the silica cladding has been efficiently sintered and shrinked on the silicon rod. The structural nature of the core and cladding materials has been studied by Raman spectroscopy in a confocal configuration using a $514.5 \mathrm{~nm}$ laser line. Examples of Raman spectra recorded at different positions of the fiber facet are reported on Fig. 2. The crystalline nature of the core 
is deduced from the well-structured Raman spectrum recorded in the core region, particularly evidenced by the peak centered around $520 \mathrm{~cm}^{-1}$ whose Full Width at Half the Maximum (FWHM) suggests a good degree of crystallization (see Fig. 2a). At the opposite, the cladding presents the well-known signature of amorphous silica (see Fig. 2b). Further studies indicate the polycrystalline nature of the core material. The large core dimension obtained here is however hardly compatible with any application in optics making a second drawing mandatory, which should be facilitated by the good quality of the obtained structure. This work is still under development today but represents a really novel route when compared to the techniques already reported in the literature. ${ }^{7}$
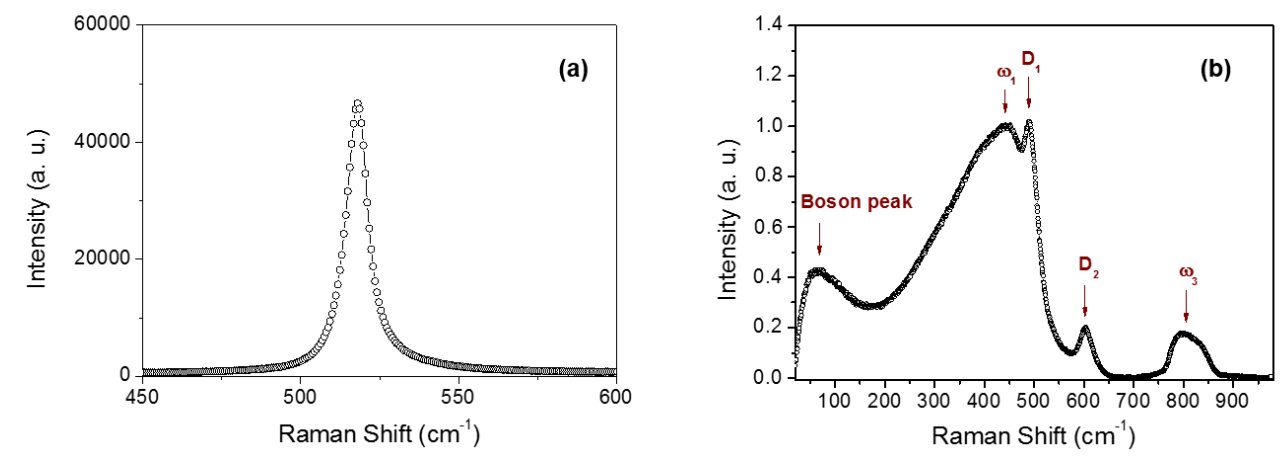

Figure 2. Raman spectra obtained when probing (a) the silicon core or (b) the silica cladding materials of the hybrid-fiber drawn from the all-solid silicon/silica preform.

\subsection{Rod-in-Stack technique}
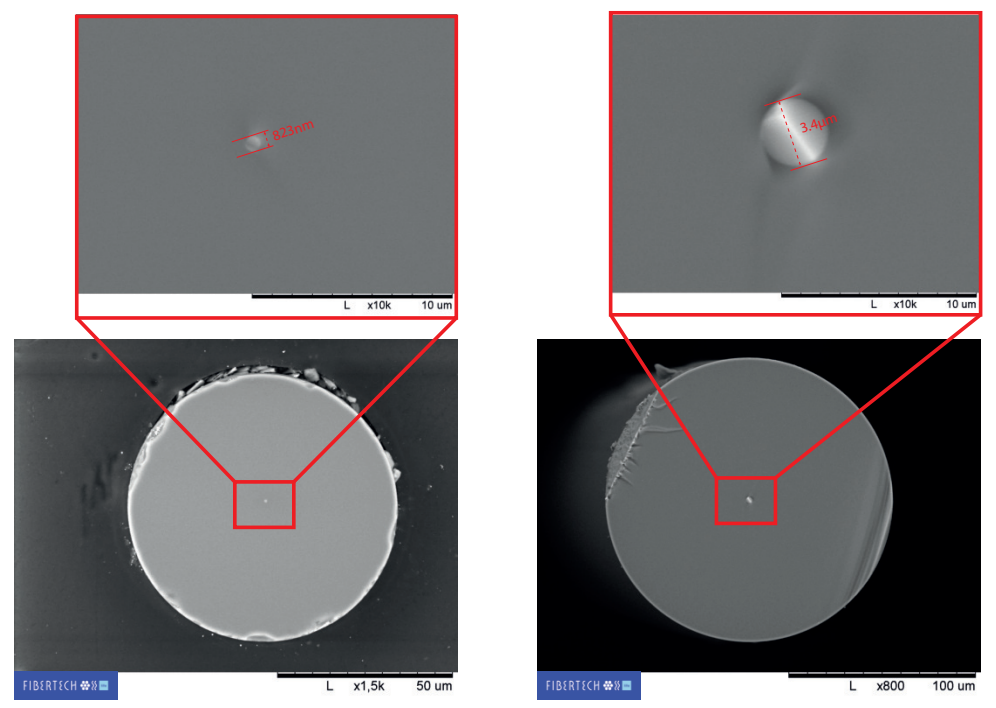

Figure 3. SEM image of two fibers obtained by the rod-in-stack technique.

The second manufacturing technique developed in this context is based on an approach derived from the MCM and based on the knowledges and skills accumulated during the last twenty years in the context of Photonic Crystal Fibers (PCFs) manufacturing. This technique will hereafter be referred as the rod-in-stack method because it consists in inserting a silicon core rod in the center of a stack made of silica capillaries, this stack then being itself sleeved into a tube. In the case of this work, the starting silicon material will be the same as in section 2.1. As is commonly done for silica PCFs, the stack is first drawn into a cane and then turned into a fiber after a second high temperature drawing. The point here is that it seems that this approach, in the 
context of a silicon/silica assembly, tends to limit the occurring of cracks during drawing. This is attributed to the air/silica cladding structure that may facilitate the absorption of the deformations that appear in the structure due to the different thermal coefficients of the two materials. One remarkable consequence of the good stability of the structure is the possibility to perform continuous drawing without interruption due to fiber breaks. It has then been possible to manufacture hundreds of meters of several fiber spans with different micrometer-sized core dimensions, the smallest one being about $800 \mathrm{~nm}$ in diameter. A view of some fibers is presented on Fig. 3. In the case of those fibers, the collapsing of the air holes of the cladding during fiber drawing permitted to obtain an all-solid structure. Such fibers, polymer coated and with good geometrical homogeneity, can be managed similarly to conventional optical fibers for optical characterizations. As an example, a cut-back measurement performed on a $1.46 \mathrm{~m}$-long starting piece of $3.4 \mu \mathrm{m}$ core fiber (then reduced to $36 \mathrm{~cm}$ ) is presented on Fig. 4. This measurement has been conducted using a conventional supercontinuum source injected into a high numerical aperture fiber butt-coupled to the fiber under test, the output light being collected by a multimode fiber connected to an Optical Spectrum Analyzer (OSA). One can note that the background losses are below $0.25 \mathrm{~dB} / \mathrm{cm}$ over a wide spectral range in the Near Infrared (NIR) region, i.e. similar to the best values reported for Silicon-On Insulator (SOI) waveguides.

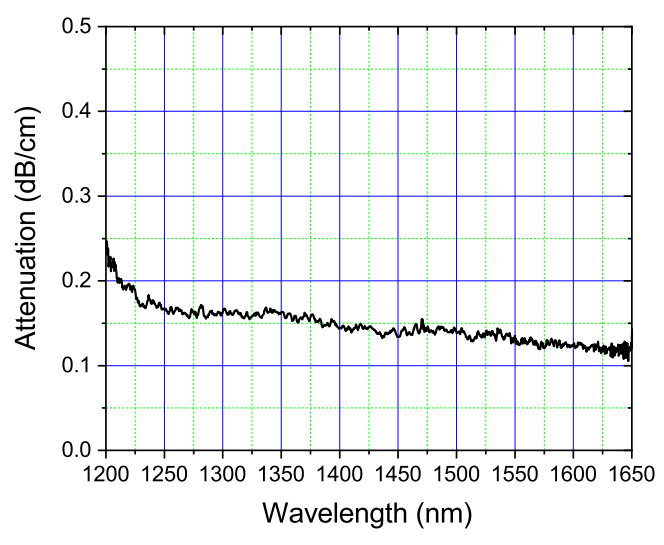

Figure 4. Attenuation curve measured on a $3.4 \mu \mathrm{m}$ diameter core silicon-core fiber obtained by the rod-in-stack method.

Additional measurement performed with a different set-up indicates that the mean attenuation is below $2 \mathrm{~dB} / \mathrm{cm}$ in Mid-IR region and that the fiber transmits light up to at least $4 \mu \mathrm{m}$ wavelength. This measurement has been possible thanks to the use of a Mid-IR supercontinuum based on a fluoride optical fiber from "Le Verre Fluoré" and compatible monochromator and detector. These remarkable optical properties are attributed to the good structural quality of the core material and of the core/cladding interface, as is illustrated by Fig. 5 .

First, several Raman spectra have been recorded at different positions in the fiber core using a confocal Raman microscope with a $532 \mathrm{~nm}$ excitation laser line. As was the case for the fiber obtained using Sol-Gel sintering, the good crystallinity of the core material is highlighted by the presence of a clear peak centered around $520 \mathrm{~cm}^{-1}$ and only observed in the core region. A deeper investigation of the fiber structure has been performed using HighResolution High Angle Annular Dark Field (HR-HAADF) imaging in Scanning Transmission Electron (STEM) microscopy of a fiber sample prepared by Focused Ion Beam (FIB) technique. In this case, a net contrast between the core and the cladding is put in evidence when analyzing a fiber facet. At this stage, it seems that the core material is poorly affected by a diffusion of oxygen from the cladding. Moreover, more information on the structure of the fiber materials is illustrated by Fig. 5 (right), which demonstrates the amorphous structure of the cladding whereas close to the core/cladding interface and in the core, monocrystalline (112) structure of silicon is clearly observed. 

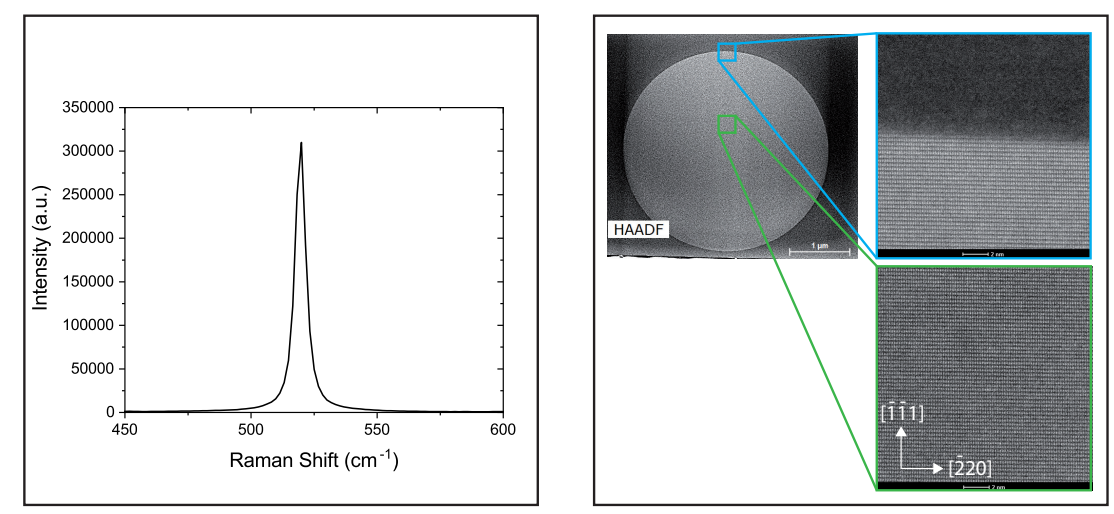

Figure 5. Left: Raman spectra recorded when probing the core of the $3.4 \mu \mathrm{m}$ core fiber. Right: TEM images recorded on a facet of a $3.4 \mu \mathrm{m}$ core fiber obtained by the rod-in-stack method.

\section{CONCLUSION}

In this paper, we reported on two techniques developed in our group so as to facilitate the obtention of good quality silicon-core optical fibers. The first one is based on the sintering of a Sol-Gel -made porous silica matrix onto a silicon rod. It permits to obtain an all-solid silicon/silica preform at a temperature smaller than the melting point of silicon. It has been shown that such a preform can be drawn into a fiber. The second technique consists in a method derived from the stack-and-draw method used to manufacture PCFs. By using a commercially available silicon rod as the central element of the stack, it has been shown that long lengths of all-solid micrometer-sized core silicon-core fibers can be obtain. These fibers exhibit very low background losses explained by the good quality of the core material and core/cladding interface, making them good support for photonics applications like broadband light sources in the Mid-IR wavelength range which represents the current trend in the field..$^{8,9}$

\section{ACKNOWLEDGEMENTS}

This work was supported by the French Agence Nationale de la Recherche: SPICY project (ANR-16-CE240015), the LABEX CEMPI (ANR-11-LABX-0007) and the Equipex Flux (ANR-11-EQPX-0017); The Ministry of Higher Education and Research, the Hauts de-France Regional Council and the European Regional Development Fund (ERDF) through the Contrat de Projets Etat-Region (CPER Photonics for Society, P4S). This work was developed at the IRCICA (USR CNRS 3380, www.ircica.univ-lille1.fr).

\section{REFERENCES}

[1] Schmidt, M., Argyros, M., and Sorin, F., "Hybrid optical fibres - an innovative platform for in-fibre photonic devices," Advanced Optical Materials 4, 13-36 (2016).

[2] Sazio, P. J. A., Amezcua-Correa, A., Finlayson, C. E., Hayes, J. R., Scheidemantel, T. J., Baril, N. F., Jackson, B. R., Won, D.-J., Zhang, F., Margine, E. R., Gopalan, V., Crespi, V. H., and Badding, J. V., "Microstructured optical fibers as high-pressure microfluidic reactors," Science 311(5767), 1583-1586 (2006).

[3] Peacock, A. C., Gibson, U. J., and Ballato, J., "Silicon optical fibres - past, present, and future," Advances in Physics: X 1, 114-127 (Jan 2016).

[4] Ballato, J., Hawkins, T., Foy, P., Stolen, R., Kokuoz, B., Ellison, M., McMillen, C., Reppert, J., Rao, A. M., Daw, M., and et al., "Silicon optical fiber," Optics Express 16, 18675 (Oct 2008).

[5] Healy, N., Gibson, U., and Peacock, A. C., "A review of materials engineering in silicon-based optical fibres," Semiconductor Science and Technology 33, 023001 (Jan 2018).

[6] Hamzaoui, H. E., Courthéoux, L., Nguyen, V., Berrier, E., Favre, A., Bigot, L., Bouazaoui, M., and Capoen, B., "From porous silica xerogels to bulk optical glasses: The control of densification," Materials Chemistry and Physics 121(1), $83-88$ (2010). 
[7] Hamzaoui, H. E., Bouwmans, G., Capoen, B., Chen, N., Douay, M., and Bouazaoui, M., "Sol-gel silica glass-cladding semiconductor-core optical fiber," Materials Today Communications 11, 179 - 183 (2017).

[8] Ren, H., Shen, L., Runge, A. F. J., Hawkins, T. W., Ballato, J., Gibson, U., and Peacock, A. C., "Low-loss silicon core fibre platform for mid-infrared nonlinear photonics," Light: Science and Applications $\mathbf{8}$ (Nov 2019).

[9] Ghosh, A. N., Meneghetti, M., Petersen, C. R., Bang, O., Brilland, L., Venck, S., Troles, J., Dudley, J. M., and Sylvestre, T., "Chalcogenide-glass polarization-maintaining photonic crystal fiber for mid-infrared supercontinuum generation," Journal of Physics: Photonics 1, 044003 (Sep 2019). 